\title{
Método em demografias históricas
}

\author{
Method in Historical Demographies
}

Heitor P. de Moura Filho.

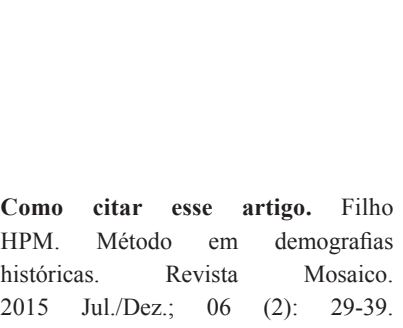

\begin{abstract}
Resumo
O texto usa o conceito de "revolução" cunhado por T.Kuhn com referências às ciências "duras", para desenvolver, por analogia, os conceitos de "método em demografia histórica" e de "degraus metodológicos", com os quais busca entender as diversas variantes metodológicas da demografia histórica. O método em demografia histórica fica definido por uma combinação de quatro componentes: um problema, as fontes escolhidaspara a análise, as técnicas de processamento dessas fontes e os resultados assim obtidos. Defende-se a validade desta definição a partir de um exame da criação da disciplina por L.Henry, para em seguida aplicá-la à obra de seus sucessores em Portugal e no Brasil. Ao contrário da evolução por contradições identificada por Kuhn nas ciências exatas, a evolução da demografia histórica se deu por modificações parciais e sem "revoluções" que destronassem sucessivos consensos vigentes. Houve, no entanto, clarasmodificações na escolha dos problemas, das fontes e das técnicas de tratamentos dos dados.

Palavras-Chave: Demografia Histórica. Método em história. Paradigmas historiográficos.
\end{abstract}

\begin{abstract}
This paper employs the concept of "revolution" coined by T.Kuhn with reference to the hard sciences to develop, by analogy, the concepts of "method in historical demography" and of "methodological steps", with which it seeks to understand the diverse methodological paths in historical demography. Method in historical demography is defined here by a combination of four components: a problem, the sources chosen for analysis, the processing techniques of these sources and the result thus obtained. This definition is validated through examination of the origins of the discipline with L. Henry, being then applied to the works of his successors in Portugal and Brazil. Differently from the evolution through contradictions identified by Kuhn in the exact sciences, evolution in historical demography is seen to have occurred through partial modifications and without "revolutions" which defied successive conventional wisdoms. There were, however, clear changes in the choice of problems, sources and techniques for treatment of data.

Keywords: Historical Demography. Method in history. Historiographic Paradigms.
\end{abstract}

\section{Introdução}

O estudo de populações do passado baseado na datação dos eventos biológico-sociais determinantes para a vida de cada indivíduo - nascimento, casamentos, partos, migrações e óbito - tem cerca de meio século de existência como uma área acadêmica definida: a demografia histórica. Tendo-se firmado de início a partir de uma metodologia específica, sistematicamente aplicada a uma multitude de acervos paroquiais e cartoriais, logo viu pesquisadores ampliarem a gama de fontes passíveis de interesse historiográfico, acarretando inevitáveis e sucessivas alterações na metodologia original. Neste processo, internacional e multidisciplinar, novos tipos de informação encontrados em fontes variadas passaram a sugerir novos temas de pesquisa, que por sua vez ensejaram novos métodos de análise. A aplicação das sucessivas metodologias espalhouse por temas correlatos à demografia, criando de fato novas áreas de pesquisa, que se mantêm em parte na demografia, mas em parte a extrapolam, como é o caso, entre outros, da história de família e da história baseada na reconstituição de redes interpessoais. A ênfase central dessas pesquisas, de originalmente demográfica, alargou-se para abarcar todos os aspectos da história social.

Seja no seu formato original, de reconstituição de famílias, seja nas suas variadas extensões que surgiram desde então, a demografia histórica nos oferece interessante trajetória de evolução científica. Procurando adaptar para a historiografia algumas das ideiasdesenvolvidas por T.Kuhn sobre "revoluções" nas ciências "duras", propomos a ocorrência de "degrausmetodológicos" que teriam pontuado esta trajetória. Como discutido adiante, em vez de alterações generalizadas em todo um ambiente científico de uma disciplina,vemos nas mudançassucessivasde componentes específicos do ambiente metodológico da demografia histórica o condutor de sua evolução 
científica. $^{1}$

Antes de propor conceitos que nos ajudem neste esforço de análise, vejamos como foi forjada, como área acadêmica própria, a combinação de demografia com história.

\section{Demografia histórica}

A demografia histórica nasceu, expandiu-se e se estabeleceu a partir da reconstituição de famílias dos séculos XVII e XVIII, épocas anteriores à existência de registros estatísticos sistemáticos. Este processo buscou identificar pessoas e as relações familiares entre elas, em combinação com o levantamento das datas para seus principais eventos vitais: nascimento/ batismo, casamento, partos e morte/sepultamento. Após este corpus de informações ter sido levantado, em trabalho lento e minucioso, os resultados que se mostrassem coerentes e que cobrissem todo um ciclo familiar eram reunidos na forma de dados demográficos que poderiam ser tratados com as técnicas demográficas tradicionais, aplicáveis a dados de qualquer época. Com estes cálculos, obtinham-se estimativas para as taxas demográficas usuais - como as de mortalidade, nupcialidade, fecundidade e de variação no tamanho da população - informações que, com referência àquelas épocas longínquas, se supunham para sempre desconhecidas, dada a inexistência dos agregados estatísticos a partir dos quais pudessem ser calculadas.

Reafirmando sua gênese a partir do problema posto, o próprio "pai" da demografia histórica, o demógrafo francês Louis Henry (1911-1991), a definiu como "a [demografia] de todas as populações do passado, próximo ou distante, sobre as quais não temos qualquer informação estatística ou somente uma informação insuficiente [nosso grifo]". ${ }^{2}$ Mais do que uma ampla "demografia do passado humano", Henry insistiu sobre a qualificação restritiva - da informação insuficiente que corresponde ao contexto e ao processo da criação de seu método. De fato, a demografia histórica só surgiu como disciplina após L.Henry identificar o potencial dos registros paroquiais, sistematizar um método capaz de extrair deles uma nova informação, incentivar sua aplicação a grande número de fundos arquivísticos e, principalmente, mostrar como empregar os resultados para resolver um problema demográfico então com relevância política: entender o comportamento da fecundidade na França do pós-guerra relativamente

\footnotetext{
1 Em The Structure of Scientific Revolutions (1962), Thomas S.Kuhn introduziu um entendimento da evolução das ciências baseado na alternância de períodos de "ciência normal", em que uma área científica se desenvolve sobre um conjunto de conceitos aceitos pela grande maioria de seus praticantes, e momentos de "troca de paradigma", em que este conjunto de conceitos comuns sofre modificações radicais, tornando-se a partir daí o novo consenso geral. Em 1977 publicou coletânea de artigos em torno da história das ciências, The Essential Tension, em que avança no tema.

2 L.Henry (1967). Manuel de démographie historique, apud Guillaume \& Poussou (1970: 21). A.Balhana e S.Nadalin (1980: 645-6) assim enunciam esta definicão: "O procedimento metodológico básico em demografia histórica consiste ma aplicação dos métodos de ańlice da demografia científica

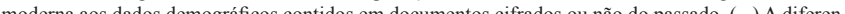
ça fintan as populações do passado, porém na necessidade que ela apresenta de elaborar seus próprios dados, de construir suas séries estatísticas.
}

àquela dos séculos anteriores.

Apesar de a demografia histórica ter-se logo tornado uma disciplina universitária pujante, seu desenvolvimento e boa parte de seu sucesso não se deveram a motivações acadêmicas. O primeiro resultado que possibilitou - esta compreensão da evolução secular da fecundidade - foi buscado através de um programa formal de pesquisas e sua metodologia bem-sucedida foi então disseminada como solução para obter informações que pudessem explicar a "bolha" de aumento de fecundidade ocorrida logo após 1945, que contrariava a tendência secular de redução, amplamente conhecida e discutida na França desde o século XIX. Quando a "bolha" perdurou, ganhando internacionalmente o nome de baby boom, as discussões no establishment estatístico francês tomaram contornos de problema institucional.No trajeto para dar uma solução acadêmica e administrativa para esta questão política, Henry valeu-se de parcerias com outros demógrafos, com historiadores, arquivistas, genealogistas, pesquisadores não acadêmicos e estudantes, além de gozar de apoio das instituições estatísticas nacionais da França. Em dois estudos clássicos na segunda metade da década de 1950, ele mesmo mostrou o que se poderia extrair do método e o formalizou em manuais largamente traduzidos. ${ }^{3}$

Dando ênfase à homogeneidade, relativamente aos dados contemporâneos, dos resultados obtidos pelo método a partir de fontes de natureza distinta das modernas, Paul-André Rosental afirmou: “....a produção, por Louis Henry, em 1958, de uma periodização contínua, que se estendia do século XVII ao século XX, marcou o nascimento da demografia histórica como disciplina". ${ }^{4}$

A originalidade da demografia histórica, assim, não disse respeito ao tipo de fonte pesquisada ou mesmo ao procedimento de reconstituição de famílias. Sua fonte básica, os arquivos paroquiais, há muito eram compulsados por genealogistas, biógrafos, historiadores regionais e até demógrafos. Cada um desses interessados, ao seu modo e com seus objetivos particulares, praticavam o procedimento central da demografia histórica, a reconstituição de famílias. ${ }^{5}$ Em 1942, um demógrafo, o sueco Hannes Hyrenius, já a havia empregado com base em listas nominativas de paróquias do Báltico para um estudo sobre a

\footnotetext{
3 Henry (1956), Fleury \& Henry (1956), Gautier \& Henry (1958), Fleury \& Henry (1965) e Henry (1967). A partir de estada de L.Henry no Brasil, dentro de projeto da UFPR, este último manual foi adaptado a certas condições brasileiras e publicado em português (Henry, 1977).

4 E mais: "O que Henry realizou foi obter a aceitação para a ideia de uma absoluta neutralidade e continuidade, estatística e demográfica; isto significava que os resultados obtidos pelos historiadores demógrafos a partir dos registros paroquiais podiam ser combinados com as estatísticas publicadas dos séculos XVIII e XIX e com as estatísticas contemporâneas estabelecidas pelo INSEE [órgão dos séculos XVIII e XIX e com as estatísticas contemporâneas estabelecidas pelo INSEE [órg Maria Luiza Marcílio expressou ideia semelhante: "A Demografia Histórica começou, em suas primeiras análises, testando o método da Reconstituição de famílias de uma paróquia ou de conjunto de paróquias, e com a finalidade expressa de calcular taxas gerais e especiais de fecundidade, de nupcialidade e de mortalidade, para populações pré-estatísticas (sem dados censitários ou quantitativos sobre sua população)". (Marcílio, 2004).

5 J.Dupaquier (1984;24-34) relata pesquisas anteriores a L.Henry de reconstituição de famílias, principalmente na Alemanha, na Suécia e nos Estados Unidos, comentando como, até então, nada havia sido feito na França: "Nestas condições o método de reconstituição de famílias precisou ser inteiramente reinventado na França, o que foi feito quase que simultaneamente por Pierre Goubert e Louis Henry."
} 
fecundidade conjugal, isto é, com a mesma meta demográfica que motivaria L.Henry quase uma década depois. O fato de o estudo ter sido escrito em sueco e de ter sido publicado durante a guerra, permanecendo isolado do restante da comunidade acadêmica europeia e de suas instituições estatísticas oficiais, no entanto, deixou seu autor no esquecimento até ser recuperado, depois do sucesso de L.Henry, como um "precursor" do método da demografia histórica. ${ }^{6}$ Podemos buscar a originalidade da demografia histórica, sim, na sua "formatação" por L.Henry, o que levou a sua rápida divulgação na comunidade acadêmica como solução metodológica para o estudo demográfico de populações pré-estatísticas. Ou seja, foram a metodologia de pesquisa e os objetivos historiográficos os fatores que impulsionaram a formação da demografia histórica como disciplina acadêmica.

\section{Uma ideiade método em demografia histórica}

Voltando ao problema de caracterizar a evolução científica na demografia histórica, percebemos que não é imediata a transposição para as ciências sociais - e menos ainda para a história - dos conceitos e dos processos epistemológicos propostos por T.Kuhn. Enquanto seu raciocínio se baseia numa sequência linear de épocas e ambientes de "ciência normal", intercalados por "trocas de paradigmas", nos quais participam, senão a totalidade, certamente a imensa maioria dos praticantes da área, o que vemos na historiografia em geral, assim como na história demográfica, é a convivência em paralelo de diversas opções epistemológicas e metodológicas. Essas opções eventualmente buscam apoio em métodos desenvolvidos em outras áreas, eventualmente coexistem em tensão entre si, mas mais comumente mostram-se alheias umas às outras. Como encontrar alguma analogia ao processo linear das ciências "duras", que convence e logo incorpora a maioria de seus praticantes, neste contexto onde não encontramos um consenso dominante e, sim, opções preferenciais quanto à forma de fazer história, que, com frequência, se pretendem independentes do que "se faz noutras áreas"?

Dentro do amplo escopo dos estudos sobre população, podemos identificar,no surgimento da demografia histórica, o que seriam seus "pilares fundadores": um problema (como analisar a evolução secular da fecundidade na França diante da falta de estatísticas no passado), fontes escolhidas (os registros paroquiais), técnicas de processamento das fontes (a reconstituição de famílias) e os resultados obtidos (a produção de uma base de informações que permitia

6 Rosental \& Mandelbaum (2003) relatam este fato, mencionando sua publicação de 1948, La mesure de la reproduction et de l'accroissement naturel, Population, 3(2):271-292. 0 calcular taxas demográficas sem recursos a estatísticas agregadas coevas). Partindo desses "pilares", procuraremosconceituar e comparar analiticamente as muitas formas de "fazer história demográfica". Para isso, definimos um método em demografia históricacomo uma combinação específica de quatro conjuntos: de problemas, de fontes, de processos de tratamento dessas fontes e de resultados obtidos pelo método. A partir deste conceito de método em demografia histórica, podemos identificar a "evolução científica" na demografia histórica não por uma sequência de "revoluções", que tivessem afetado toda a disciplina, mas por degraus metodológicos, que alteramum ou mais dos conjuntos definidores de cada método. Ao contrário dos processos analisados por Kuhn, essa "evolução científica" da demografia histórica não exige que todos seus praticantes acompanhem cada novidade, nem mesmo que considerem a mudança relevante para suas pesquisas.

Podemos analisar a própria criação da disciplina, com Louis Henry,já como integrando esta "evolução por degraus". Valendo-se de registros paroquiais, fontes conhecidas e empregadas por profissionais de outras especialidades, L.Henry estabeleceu um processo metodológico (a reconstituição de famílias) que se valia de etapas quase idênticasà prática dos genealogistas. Entretanto, enquanto estes tinham por objetivo simplesmente identificar os membros de certas famílias, a partir de suas respectivas datas e locais de nascimento, casamento e óbito,L.Henryseguiu adiante, incorporando os tradicionais indicadores da demografia a esses resultados inciais, com o objetivo de resolver um problema (estimar a fecundidade do passado francês) completamente diferente do que motivava os genealogistas.Assim, os impressionantes resultados a que chegou por este novo caminho metodológico em nada se assemelhavamàqueles obtidospor genealogistas ou historiadores regionais.

Ao deparar-nos com tão inesperado resultado, num contexto que se afigurava impedir para sempre o conhecimento dessas informações do passado, de fato parece estarmos vivenciando uma "revolução científica" ou, como se prefere denominar, uma mudança de paradigma. Mas, ao contrário das "revoluções" nas "ciências duras", L.Henry não criou uma nova teoria, nem conceituou pela primeira vez algo desconhecido. Empregou fontes conhecidas e organizou informações aí encontradas de modo semelhante ao que outros já faziam há muito. Também não desenvolveu as técnicas demográficas, mas teve, sim, a ideia de empregar essas técnicas existentes aos dados que poderia calcular em suas fontes genealógicas. Tampouco produziu uma argumentação explicativa diferente daquela que seria empregada por demógrafos. Tendo aplicado a seus dados as técnicas demográficas tradicionais, desenvolveu seu raciocínio e sua argumentação da mesma maneira 
que poderia ter feito um demógrafo que não soubesse em que época viveram as populações que analisava. $\mathrm{O}$ resultado a que chegou, contudo, foi inovador e emblemático: informava sobre a dinâmica populacional de populações pré-estatísticas na França, analisando-a como se tivesse acabado de descobrir um esquecido censo em padrões modernos promovido por Colbertno século XVII. Dava-se o salto paradigmático.

Em decorrência dessa possibilidade de obtenção pela demografia histórica europeia de estatísticas fidedignas, cobrindo épocas pré- e proto-estatísticas, houve uma natural extensão dos interesses, dos métodos e das técnicas demográficas modernas aos dados levantados por pesquisadores focados em épocas mais remotas. Formou-se, assim, um contínuo estatístico e explicativo que se expande para trás a períodos anteriores àqueles para os quais dispomos de levantamentos censitários e dados estatísticos confiáveis. Talvez seja esta a principal realização extra-muros do projeto original de Louis Henry: seus métodos e as extensões que geraram foram capazes de extrair do passado estatísticas suficientemente precisas para se acoplarem, em pé de igualdade, àquelas obtidas modernamente por censos e pesquisas amostrais detalhadas. As pesquisas desenvolvidas na Europa geraram impressionante densidade de estudos monográficos e de análises de registros com cobertura nacional, resultando, de imediato, num conhecimento detalhado das múltiplas transições demográficas europeias, o que talvez seja hoje o carro-chefe dos resultados da demografia histórica.

Em pouco mais de meio século de existência como uma disciplina acadêmica estruturada, mais do que produzir estatísticas confiáveis referentes a épocas passadas, a história demográfica havia adquirido seus atuais foros historiográficos, que extrapolam os métodos estritamente demográficos e os resultados tipicamente esperados deles, ao expandir-se em diversas dimensões. A disciplina avançou sobre tipos diversos de fontes; sobre períodos que remontam, com abrangência, a cinco séculos e, pontualmente, a milênios; sobre temas que extrapolaram o estritamente demográfico para abranger variados aspectos familiares, sociais, econômicos e também biológicos; sobre técnicas que extrapolaram a simples reconstituição de famílias, para acompanhar a evolução metodológica da demografia moderna; e sobre contextos sociais os mais diversos, em todas as regiões do planeta.

\section{A força das fontes}

A demografia histórica, é claro, não foi estabelecida, nem vingou, num vácuo. Não só outros profissionais, além dos historiadores, desde muito, abordavam temas ligados a população, masos historiadores, no seu dia-a-dia, conviviam com os interesses e trabalhos das ciências sociais. O método de L.Henry, no entanto, manteve-se infenso a este entorno durante quase duas décadas, coexistindocom a história das populações e a história social sem se ver afetado em sua metodologia. Viu surgir e expandir-se, também, toda a onda historiográfica em direção às particularidades da vida humana e ao pós-modernismo, iniciada com a história das mentalidadese suas variantes. Embora este modo de fazer história tenha crescido a ponto de relegar a história econômica e social nos moldes annalistes a um rincão bem distante do centro das atenções, o método de reconstituição de famílias não foi diretamente afetado pelas "novas histórias". Cremos que, quando o método L.Henry veio a seralterado, isto ocorreu devidomais a suas próprias "contradições internas" quanto à produtividade do trabalho de pesquisa e quanto à representatividade de seus resultados. ${ }^{7}$ Além dessas críticas, também vemos na diversidade de tipos de fontes e da consequente diversidade das informações disponíveis nelas, agora à mão do historiador, outroimportante impulso para as primeiras modificações conceituais ao seu método.

Tendo seus objetivos e suas técnicas sido desenvolvidos em função do contexto social e jurídico europeu e particularmente francês, seu método sofreu um primeiro abalo ao ser aplicado aambientes históricos, em Portugal e no Brasil, com características suficientemente distintas para repercutir sobre a precisão técnica do método. Nesses países, percebeuse a necessidade de procedimentos mais robustos de identificação de indivíduos, dada a prevalência de práticas sociais comuns, como a falta de regras rígidas para nomeação de filhos, a frequente repetição de nomes de batismo, a alta incidência de homônimos e a grande proporção de nascimentos fora do casamento (este último, no Brasil). Nas palavras de M.L.Marcílio, ao comentar a multiplicidade de combinações de nomes de família em São Paulo: "Todo trabalho de reconstituição das antigas famílias paulistas seria uma aventura de índole policial ou simplesmente uma tarefa para genealogistas absortos em reconstituir algumas árvores genealógicas 'patrícias', donde talvez mais fáceis de recuperar" (Marcílio 1968:92). ${ }^{8}$ Além desta dificuldade de identificar e de acompanhar pessoas pelo nome de família, a irregularidade de sobrevivência das fontes passíveis de serem seriadas e, frequentemente, sua inexistência levaram os pesquisadores no Brasil a deixar de lado o método original de reconstituição de

\footnotetext{
7 Jacques Dupâquier (1984) lembra que, em 1971, M.Livi Bacci já criticava o tempo dispendido nas pesquisas relativamente a seus resultados. Faz um apanhado da produtividade na reconstituição de ferlis, a live

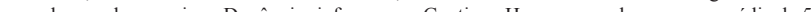
numa deze de pesquis. De De registros em Crulai para obter cada uma de suas 214 fichas de famílias. O amplo programa do INED, por sua vez, conseguiu baixar esta média para 25 registros para cada uma de 12.000 fichas (com 300.000 registros)

8 Sobre a adaptação do método para Portugal e para o Brasil, ver Balhana \& Nadalin (1980), Balhana (1987), Amorim (1991), Marcílio (2004) e Scott (2007).Em sua tese sobre a cidade de São Paulo, M.L.Marcílio (1968: 81-96)reforça essas dificuldades quanto à identificação de indivíduos seja pelo nome de família, seja pelos prenomes, lembrando adicionalmente que as lacunas nas fontes, falta de anotação de idades, a frequente ausência de registro de crianças falecidas e a falta de nome de familia par âs famílias “ ". estes métodos [de L.Henry] são válidos para países nos quais os registros civis contêm as informações indispensáveis a sua aplicação. Ora, isto não é o caso para nossa documentação sobre São Paulo, onde faltam dados essenciais."
} 
famílias com o objetivo único de anotar seus eventos vitais, em prol do levantamento de informações a partir de qualquer tipo de fonte disponível, com o objetivo de "cercar" seus protagonistas e seu tema seja onde puderem encontrar alguma informação relevante.De fato, foram poucos os estudos de reconstituição de famílias no Brasil baseados essencialmente em registros paroquiais. $^{9}$

Como insistiu Altiva Balhana (1986:19-62): "Os dados conhecidos para a demografia do passado colonial brasileiro são, em geral, fragmentários e descontínuos, além de se apresentarem revestidos de pouca credibilidade. Deste modo, não se tem a visão integral das suas estruturas demográficas e muito menos da dinâmica da sua população."As capitanias e províncias de São Paulo e de Minas Gerais mostraramse excepcionais entre as regiões brasileiras em termos de disponibilidade de fontes, por terem sido objeto de sistemáticos levantamentos populacionais ao longo dos séculos XVIII e XIX, o que proporciona inestimáveis dados aos pesquisadores. Como exemplos de estudos baseados fundamentalmente em listas nominativas, podemos citar os de Luna e Klein (2005) sobre São Paulo e os de Luna, Costa e Klein (2009) sobre São Paulo e Minas Gerais.

$\mathrm{O}$ método que se revelou mais produtivo no Brasil foi a combinação de fontes, em que listas nominativas sequenciais complementavam os registros paroquiais ou, mais frequentemente, serviam de base para a reconstituição, sendo complementadas, quando possível, pelos registros vitais. Esta forma de reconstituição parcial de famílias foi realizada nos estudos da população do litoral paulista por Maria Luíza Marcílio (2006[1986]), das famílias de tropeiros de Sorocaba (Bacellar 2001[1994]), da elite agrária do Oeste Paulista (Bacellar 1997) e da população dos campos paranaenses (Machado 2006).

Assim, ampliou-se o leque de fontes utilizadas para além dos registros demográficos de batismos, casamentos e sepultamentos. Têm sido regularmente compulsadas tanto fontes com registros múltiplos, como as listas nominativas, róis de confessados ou livros de movimentação de pacientes em hospitais, quanto fontes massivas de registros individuais, como arquivos notariais e judiciais. Fontes pontuais, como arquivos de associações profissionais ou religiosas, de fazendas e de empresas também vêm sendo pesquisados com sucesso..$^{10}$ Esta disponibilidade de uma ampla gama de informações potencialmente referenciadas aos mesmos indivíduos levou ao inevitável cruzamento de dados até então desconexos, permitindo estudos multi-geracionais ou prosopográficos, além de adensar os bancos de dados acumulados em pesquisas sucessivas. Essas pesquisas

9 Um exemplo pioneiro foi a tese de S.O Nadalin (1978) na EHESS, sobre a comunidade luterana no sul do Brasil, expandido em diversos trabalhos nos anos seguintes, por exemplo (Nadalin, 1988, 2003).

10 Para uma discussão dos vários tipos de fontes, ver Bacellar (2014) anotam todas as informações relativas a cada indivíduo, sem dúvida com a meta de compilar séries quantitativas, mas sem esta preocupação exclusiva. Um fato importante referenciado a um único indivíduo, conhecido em outras de suas características,poderá ser aproveitado, mesmo sem que se conheçam fatos análogos sobre outros indivíduos, o que teria permitido a análise agregada desses dados para o conjunto de indivíduos.Isto é, para ser relevante, o indivíduo não precisa fazer parte de um conjunto de semelhantes cujas características sejam tratadas estatisticamente. Sob esta nova perspectiva, é considerado relevantesimplesmente por integrar uma família, uma rede social ou ser membro de um grupo delimitado (elites, comerciantes, funcionários, escravos etc.).

Esta expansão no tipo de fontes empregadas foi inicialmente adotada por pesquisadores com dois objetivos metodológicos distintos. Um primeiro foi a ampliação de fontes para a obtenção do mesmo conjunto de dados vitais preconizado por L.Henry, com o mesmo objetivo de cálculo de indicadores demográficos, o que, sem dúvida, não chegava a constituir um "salto paradigmático", embora configurasse uma clara extensão do método original. A chamada "reconstituição de paróquias" praticada em Portugal por Norberta Amorim (1991, 2008) seguiu neste direção, de procurar obter as informaçõesdemográficas a partir de qualquer fonte disponível. ${ }^{11}$ No entanto, a disponibilidade, nessas fontes adicionais, de outros tipos de informação, passíveis de registro num mesmo momento de pesquisa, ofereceu aos pesquisadoresa possibilidade de levar adiante uma alteração mais radical de método, envolvendo mudanças não só no conjunto de fontes empregado, mas também no problema historiográfico motivador da pesquisa e nas técnicas empregadas. Essa alteração, ao contrário da anterior, pode ser considerada sem dúvida como um "degrau metodológico", que modificou não só a técnica de processamento de dados proposta por L,Henry, mas trouxe, embutida nela, inevitáveis alterações nos objetivos da pesquisa e nos resultados obtidos. Enquanto em Portugal também se buscou esta expansão de método (Amorim, Durães e Ferreira 2003), os trabalhos de Ana Silvia Scott fizeram uma ponte entre a experiência portuguesa com a reconstituição de paróquias com objetivos essencialmente demográficos e as atuais pesquisas no Brasil, também com reconstituição de vidas individuais, mas com objetivos mais amplos de história social (Scott 1995, 1999, 2006, 2007, 2014; Scott e Scott 2013).

\footnotetext{
11 Nas palavras da própria N.Amorim: "O fascínio pelas fontes paroquiais por parte dos licenciados em História da década (...) de 1960, principalmente na Universidade de Coimbra, resultaram em largas dezenas de trabalhos (...) com grande curiosidade hisórica, mas sem reconstituição de famílias e sem a subsequente análise de comportamentos demográficos. Eu própria tive a grande oportunidade de (...) em 1971 apresentar na Faculdade de Letras do Porto o primeiro trabalho baseado na reconstituição de famílias de Antigo Regime (...) Note-se que o obstáculo que Virgínia Rau encontrava na reconstituição de famílias em Portugal derivava do facto de não haver em Portugal, até épocas recentes, uma transmissão linear de apelidos de pais para filhos, sendo a partir dos apelidos epocas recentes, un que se reco (Nessa altura, como hoje, perseguia o indivíduo, inserido numa cadeia geracional. A Henry interessava sobretudo a família conjugal." (Amorim, 2008)
} 
Alterações de aparência simples, como a transferência do foco de pesquisa da família para o indivíduo e o uso dos dados assim obtidos para análises diferentes das demográficas, trouxeram, entretanto, uma mudança radical na perspectiva epistemológica do historiador. Ao atirar-se neste novo ambiente, precisou adotar novos conceitos e técnicas analíticas, para tratar dos novos temas que os dados lhe impunham. Saía da perspectiva agregada dos indicadores demográficos, onde indivíduos são meros componentes da informação estatística, para uma perspectiva individualizada, onde o raciocínio historiográfico, mesmo considerando as estatísticas agregadas, passa a levar em conta as relações e as trajetórias de cada indivíduo pesquisado, que se tornam o principal foco de atenção.Na expressão de Machado, Engemann e Florentino (2003), “... nem sempre - ou quase nunca - a visão do conjunto esgota as possibilidades de conhecimento de um fenômeno histórico".

\section{Perspectivas macro e micro na demografia histórica}

Na década de 1950, seja no círculo gravitacional dos Annales, seja nos círculos anglo-saxões e europeus em geral, o ambiente nas comunidades acadêmica voltadas para ahistória era deentusiasmo com a renovação intelectual em curso. D.Glass e D.Eversley, no prefácio a sua clássica antologia Population in History. Essays in Historical Demography, publicada em 1965, dão testemunho disto:

\footnotetext{
Desde os anos 1950, historiadores têm-se preocupado crescentemente com o fator populacional nas mudanças econômicas e sociais. Demógrafos, por sua vez, têm prestado mais atenção à história. E os praticantes das duas áreas começaram a trabalhar juntos, empregando suas abordagens combinadas numa tentativa de avaliar e explicar o crescimento da população experimentado pelo Ocidente desde o século XVII. Existe, é claro, uma longa tradição de interesse na história da população. Mas o interesse atual provavelmente será mais persistente e bem mais proveitoso em suas consequências. Novos estudos estão sendo iniciados em muitos países. E, como estes estudos são mais bem informados e sistemáticos do que os anteriores, já provocam continuada expansão das pesquisas. (Glass \& Eversley 1965:v)
}

De fato, vivia-se então, entre os muitos praticantes da historiografia, uma forma de consenso que talvez mais se tenha assemelhado aos consensos abrangentes das ciências "duras". Fossem os annalistes franceses, os quantitativistas norte americanos, os empiristas ingleses ou os marxistas de todas as origens, todos consideravam que história se fazia essencialmente nas generalidades e não nas individualidades ou, como se passou a dizer a partir da convivência da história quantitativa com a teoria econômica, mais no "macro" do que no "micro".
Neste consenso, qualquer história micro ainda estava integralmente associada à história événementielle, factual e sem pretensões teóricas, relegadas pelas "locomotivas" do pensamento histórico aos ultrapassados biógrafos, historiadores regionais e historiadores de eventos momentosos.A história relevante deveria ser feita a partir dos agregados, cuja análise revelaria as generalidades dignas de nota.O próprio método desenvolvido por L.Henry empregava a informação micro, nominativa, mas o fazia unicamente como recurso de identificação, antes de agrupar indivíduos em famílias e de classificar famílias em grupos sociais categorizados, de onde provinham os indicadores demográficos agregados que eram o objetivo final de seu esforço. Nesses estudos generalizantes, população e, portanto, demografia tinham papel decisivo, pois "encarnavam" o coletivo de indivíduos. Entender população e demografia significava, para todos, um importante passo para entender as coletividades humanas.

Neste ambiente,o método de reconstituição de famílias surgia como mais uma técnica, entre tantas outras disponíveis aos estudiosos, para trabalhar as fontes existentes. O objetivo principal era o conhecimento das sociedades através de seus múltiplos aspectos, entre os quais a população tinha lugar determinante. Não havia, portanto, qualquer "exclusividade" ou mesmo "prioridade" para o método no âmbito da história social. Eram a quantidade e variedade de fontes disponíveis, sem dúvida, as principais restrições à forma e à abrangência da pesquisa. Contemporâneos de L.Henry produziram estudos sobre populações do passado europeu empregando registros paroquiais, mas também, quando possível, grande gama de outras fontes. Além destapreferência pelo geral sobre o particular, uma segunda ênfase metodológica residia na comprovação quantitativa dos fenômenos demográficos e sociais. ${ }^{12}$

Pierre Goubert produziu na década de 1950 sua clássica históriasocial e econômica do Beauvaisis nos séculos XVII e XVIII, de inspiração claramente annalistee centrada em fontes demográficas. Decorrente de longas pesquisas, seus estudosconstroem os indicadores demográficos principalmente a partir da agregação de dados nos registros paroquiais e de alguns levantamentos populacionais(Goubert 1952, 1968).A históriade J.Nadal e E.Giralt (1960) sobre a população catalã de 1553 a 1717 também é interessante neste sentido, pois ilustra como também eles "fizeram demografia histórica" de forma abrangente, sem, no entanto,empregar o método de reconstituição de famílias. O período escolhido por estes autores é exatamente um intervalonão coberto pelos levantamentos censitários na

\footnotetext{
12 Rápida nota de P.Goubert, ao final de um artigo sobre registros paroquiais, dá bem o tom da época (com nosso grifo): "Não pudemos incluir o artigo de P.Ariès publicado em Population, 1953, no3. Trata precisamente das origens do birth control. Utiliza interessantes fontes, mas (953, nas somente lit (Ge por

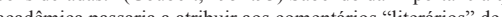
cadêmica passaria a atribuir aos comentários "literarios" de Ariès, percebemos a força da clivagem metodológica em crescimento.
} 
Catalunha, que se iniciam em meados do século XIV. Embora tais censos estabeleçam os marcos inicial e final de seu período de estudo, os autores empregam,além de registros paroquiais, uma variedade de fontes encontradas emarquivos nacionais, departamentais, diocesanos, notariais e de um hospital em Barcelona. A partir delas, além da dinâmica demográfica usual (nascimentos, casamentos e mortes), conseguem analisar em profundidade os complexos fluxos migratórios entre a França e a Catalunha no período, o que sempre foi um problema sério para a reconstituição de famílias.

$\mathrm{Na}$ Inglaterra, onde as condições sociais (multiplicidade religiosa e grande intensidade migratória) e das fontes (irregularidade de registro, deficiências na informação registrada e de preservação de arquivos) restringiam gravemente os procedimentos de reconstituição de famílias com base em registros paroquiais como proposto por L.Henry, os historiadores demógrafos optaram por fontes substitutas: genealogias da nobreza, utilizadas por T.H.Hollingsworth (1964, 1965), e metodologias agregativas, empregadas pelo Grupo de Cambridge. ${ }^{13}$

Em todos esses casos, os objetivos eram generalizantes. Vemos, além do mais, que a oposição entre micro e macro atravessa todosos "pilares"propostos aqui. Os problemas então considerados válidos eram problemas "macros". As fontes prioritárias eram aquelas que pudessem gerar dados massivos, capazes de serem analisados estatisticamente ou, pelo menos, quantitativamente. As técnicas a serem aplicadas eram, igualmente, aquelas desenhadas para produzirconclusões sobre dados agregados. Os resultados buscados, portanto, não podiam deixar de estar associados aos aspectos macros, agregados, generalizantes, em oposição a conclusões sobre indivíduos ou pequenos grupos.

No entanto, ao coletar informações outras que as datas necessárias para a reconstituição de vidas individuais, o pesquisador havia silenciosamente alterado seu problema historiográfico - que deixava de ser exclusivamente demográfico - evia-se diante do amplo leque de opções da história social. Simultaneamente a este processos de ampliação de fontes e temas pesquisados, donde de métodos para tratálos, o trabalho com fontes que permitem a identificação e o acompanhamento de momentos registrados na vida de indivíduos trouxe também a possibilidade de estudos de trajetórias individuais - fossem elas as biológicas ouas sociais - em oposição aos estudos de grupos sociais agregados. Assim, indivíduos e grupos de indivíduos (famílias e grupos sociais) passaram a ser o foco de análise, não mais como simples "unidade" num conjunto cuja principal característica vinha a ser

13 Como notou E.A.Wrigley (1966: 96-159), um dos fundadores deste grupo em 1964, embora gerando dados bem mais complexos, o esforço de levantamento de famílias é pelo menos cem vezes maior do que o de meramente contar eventos vitais, para ser anotados em planilhas. Além do esforço de levantamento, a cobertura de famílias efetivamente reconstituídas, relativamente à população total de uma região, é usualmente pequena. Para um detalhado resumo do Cambridge Group for the History of Population and Social Structure, ver Scott (2013). o total de elementos que continha, mas em si, como vidas específicas, descritas e analisadas por seu próprio interesse e como representantes da sociedade onde se situavam.

Ao contrário da antiga história événementielle, no entanto, o objetivo agora não era a simples descrição biográfica. Cada vida era individualizada, mas sempre vinculada a seu contexto social e, principalmente, às demais vidas coevas que pudessem ser identificadas. $\mathrm{O}$ agregado ressurgia não mais como conjuntos homogêneos quantificados, mas como conjuntos de pessoas ligadas por relações familiares, sociais, profissionais, econômicas ou políticas. A biografia individual deixava de ser um fato histórico único para se tornar representativa de um grupo, de um contexto ou de uma época. Este processo metodológico evoluíu por caminhos variados, desde a microstoria iniciada na Itália, incluindo, entre outras abordagens, a do ciclo vital, a da história de família e a de redes sociais.

\section{Da história agregada à história individual reagregada}

Vemos, assim, que a demografia histórica, em dois de seus pilares (fontes e técnicas de tratamento), sobreviveu ao "envelhecimento"do método L.Henry estrito, amoldando-se, em seus outros pilares (problemas e resultados), a novos valores.Sem procurar resenhar o amplo espectro de abordagens que se originaram da demografia histórica ou que fazem algum uso dela dentro de sua metodologia, exemplificamos,com as formas de tratar a instituição do casamento em alguns métodos diretamente vinculados às técnicas da demografia histórica, esta passagem de um foco no agregado estatístico para um foco no micro como “individual agregável”.

Podemos começar por L.Henry, para quem o casamento na Europa dos séculos XVII e XVIII era o locusessencial de reprodução da sociedade,dados os baixíssimos índices de natalidade extraconjugal.Em vista desta centralidade, caberia à demografia histórica verificar os indicadores etários e temporais determinantes da maior ou menor fecundidade completa das mulheres, taxa com repercussão direta sobre o crescimento populacional. Assim, examinou a proporção de celibato definitivo, a idade média ao primeiro casamento, o tempo decorrido entre o casamento e o primeiro parto, os sucessivos períodos intergenésicos, a idade fértil média e a idade ao último parto. A partir dessa plêiade de indicadores, verificou que a população francesa aumentava só lentamente devido a uma natalidade total insuficiente para compensar a alta mortalidade sofrida em todas as idades, mas principalmente pelas crianças. Apontou, também, como a prática de casar numa idade já madura (em torno de 24 anos para as mulheres e 
28 anos para os homens) ajudou a manter restrita a natalidade total naquela sociedade. Estudos do tema foramrealizados sobre toda a Europa da Idade Média até 1900 por J.Hajnal em trabalhos hoje clássicos, iniciados em 1953, mas cuja formulação definitiva aparece em Hajnal (1965). Neste texto, Hajnal define o que seria um "padrão europeu de casamento", caracterizado fundamentalmente por primeiros casamentos tardios e uma alta proporção de celibato definitivo. Com a evolução desses estudos, inclusive através de uma importante pesquisa coletiva do Office of Population Research, da Universidade de Princeton (Coale\& Watkins 1986), convencionou-se separar as populações em que este padrão seria determinante daqueles em que vigoravam outras práticas nupciais, por uma linha imaginária que cortasse a Europa desde o Mediterrâneo, próximo ao norte da Itália, até São Petersburgo, ficando as populações a leste desta linha fora do "padrão europeu". Em todos esses estudos as técnicas da demografia histórica eram instrumentais para se chegar a conclusões estritamente demográficas sobre idades, períodos e taxas médias de fecundidade, em seguida aproveitadas, pelos mesmos ou por outros autores, para ilações sociológicas sobre as sociedades em questão (por exemplo, quanto à necessidade de independência econômica como requisito para o casamento e vida num domicílio separado de suas respectivas famílias). Partia-se de dados individualizados, que, uma vez adequadamente classificados, seriam agregados nessas categorias, cujos indicadores estatísticos apontavam para regularidades coletivas. Ainda se aplicavamcanonicamente, portanto, as regras da demografia histórica tradicional. ${ }^{14}$

Numa etapa posterior, já marcados pelas prioridades epistemológicas das "novas histórias", os mesmos indicadores demográficos ou outros obtidos por técnicas semelhantes conduziam a busca por novas questões sociais: formas usuais de arranjos nupciais e de compadrio entre os vários grupos sociais, existência ou não de práticas contraceptivas dentro dos casamentos, correlação entre grupos sociais e profissionais a que pertenciam os noivos e seu grau de alfabetização e de "numerização" (i.e. sua familiaridade com números e operações aritméticas), entre tantos outros problemas abordados a partir de indicadores demográficos agregados. Tais resultados, inicialmente cobrindo comunidades isoladas, foram paulatinamente refeitos em múltiplos estudos monográficos, eventualmente complementados por registros massivos, logo permitindo analisar as mesmas conclusões para regiões maiores e até para populações nacionais ou plurinacionais.As técnicas da demografia histórica tornavam possível

14 É interessante notar, com M.Sílvia Bassanezi (1994), que "a nupcialidade, como uma variável de controle da fecundidade no Brasil, não tem a mesma importância e significado verificados para o noroeste europeu, ou seja, a de conter a reprodução da população." Aqui as mulheres casavam mais moças, tendo vida fértil mais longa, e havia uma alta frequência de uniões consensuais, fora da instituiç̃̃o religiosa do casamento. Além do mais, a própria pesquisa demogŕfica prelinina a con 列 demografia, "onde o qualitativo e o quantitativo se complementem". fazer-se história da família e história social em geral para épocas e regiões sobre as quais não havia fontes diretamente vinculadas aos problemas estudados. O salto paradigmático de L.Henry se havia estendido a novos temas e passava a ser útil a outras disciplinas, como a antropologia, a sociologia e mesmo a psicologia.

Neste processo de diversificação de interesses e métodos, é interessante cotejarmos três das múltiplas vertentes da história social em que percebemos claras heranças da demografia histórica: a) a análise social a partir da combinação de conjuntos estatísticos e de trajetórias individuais, b) aanálise a partir da identificação de redes sociais e c) a análise a partir de modelos do ciclo de vida. Em todos os casos, não há escolha de fontes preferenciais: qualquer fonte, agregada ou pontual, que traga informação sobre um tema, sobre um grupo social ou sobre um indivíduo, será bem-vinda e aproveitada no que tem a oferecer ao historiador. Tampouco é forçada uma segregação de procedimentos, fazendo-se eventualmente uso, em cada abordagem, de técnicas e conceitos desenvolvidos com outras prioridades. As formas do raciocínio historiográfico, no entanto, mostram-se essencialmente distintas.

No primeiro caso, os argumentos estatísticos derivados de conjuntossociais servem como contexto para e, eventualmente, como indício da existência de certa situação. A associaçãodesigual entre relações conjugais não sacramentadas e a condição social no Paraná é discutida por C.Machado (2006) partir de várias modalidades de estatísticas agregadas: percentuais crescentes de casados e viúvos para as sucessivas categorias "cativos", "livres de cor" e "livre"; maiores percentuais de batizados de crianças ilegítimas filhas de mães escravas do que entre crianças filhas de mães livres; ou ainda devido à existência de casamentos entre cativos unicamente nas grandes escravarias, pertencendo ambos os cônjuges a um mesmo proprietário. Este último dado foi montado a partir de casos individuais, nominados, ou seja, a partir da perspectiva que denominamos de "micro", o individual representativo de uma categoria. Esta perspectiva micro permite, entre outras análises, identificar relações cuja informação bruta consta nas fontes (no caso, as listas nominativas), mas que requer o olhar do historiador atual para serem separadas, tornando-se nova estatística. É o caso da questão da origem social de cada cônjuge em casamentos mistos (um livre e outro escravo), aferida a partir de sua naturalidade, cor ou pertencimento a família do local. Esta última forma de raciocínio já emprega em parte a técnica de remontagem de redes (no caso, as famílias).

A identificação de redes sociais é realizada a partir da combinação de diversas fontes, para mapear certos indivíduos em momentos variados de sua vida, o que permite que sejam acompanhados em suas múltiplas relações,tanto familiares, como nas suas demais relações interpessoais. $\mathrm{O}$ registro de tais relacionamentos 
não se prende a objetivos demográficos, mas sim ao entendimento dos grupos estruturados a que pertenceu cada indivíduo. Encontramos no texto em que J.Fragoso (2001) discute a formação das elites senhoriais do Rio de Janeiro um exemplo desta abordagem, em que casamentos de indivíduos de certo grupo são identificados semelhantemente ao que faz a demografia histórica tradicional, sendo esta informação empregadano argumento historiográfico, contudo, de forma bem diferente. $\mathrm{O}$ argumento parte da identificação de grupos definidos seja por sua participação na conquista das terras circunvizinhas à cidade, seja por sua propriedade dos principais ativos produtivos naquela sociedade, os engenhos de açúcar e aguardente, seja ainda por sua atuação como funcionários do Rei ou membros da Câmara Municipal. O elo explicativo segue justamente a genealogia, identificada principalmente pelo casamento de filhas de um grupo (usualmente dos conquistadores) com homens de outro (funcionários reais sem posses materiais ou comerciantes com capital). No que as fontes são capazes de informar sobre as genealogias, o argumento acompanha a trajetória de filhas, genros, netos e sobrinhos ao casarem endogamicamente ou com membros de outros grupos que apresentem vantagens patrimoniais para a família. Na medida permitida pelas fontes, são reconstituídas essas trajetórias familiares, não mais com objetivo demográfico, mas sim para perseguir os elos patrimoniais (tanto no sentido econômico como no político).

Esta análise, embora contenha importantes elementos referentes ao ciclo vital dos indivíduos retratados, trata de indivíduos personalizados. O fato de serem agrupados e contados não lhes retiraesta característicadeindividualidade. Noqueseconvencionou chamar de "análise do ciclo vital", no entanto, a intenção é diversa, focando sobre grupos qualificados sob algum aspecto, mas individualmente anônimos. $\mathrm{O}$ objetivo analítico é o entendimento dos momentos de transição entre fases da vida, sejam elas biológicas (nascer, morrer, ter filhos), sejam sociais (sair da casa dos pais, casar, migrar etc.). A partir das trajetórias anônimas, mas classificadas e agrupadas, extraem-se conclusões estatísticas sobre o grupo analisado: sequência de fases, duração em cada fase, gatilhos desencadeadores de mudanças etc. ${ }^{15}$ Trata-se, no entanto, de abordagem que requer grande número de dadospara dar significado estatístico aos cálculos, o que tem restringido sua aplicação a períodos contemporâneos.

Como momento definidor de diversas vidas (a dos próprios cônjuges, a dos respectivos pais cujas casas estes deixam e a dos futuros filhos), o casamento assume importância focal na maior parte dos estudos de ciclo de vida. Tanto assim, que há numerosa literatura sobre o ciclo vital das famílias, visto como a conjunção dos

15 J.Kok (2007) faz interessante resenha dos procedimentos e problemas da abordagem do ciclo vital. diversos ciclos de vida de seus membros. Os principais temas são a caracterização do ciclo vital familiar, da variedade de estruturas familiares e suas consequências econômicas e dos eventos desestruturadores da unidade familiar. ${ }^{16}$

\section{Conclusão}

Cremos ter apontado aqui algumas das múltiplas formas como "as demografias históricas" se desenvolveram no último meio século, partindo das restritas condições propostas por L.Henry. Ao contrário da evolução identificada por Kuhn nas ciências exatas, a evolução da demografia histórica se deu gradualmente e sem "revoluções" que destronassem o consenso vigente. Houve, no entanto, claras modificações na escolha dos problemas, das fontes e das técnicas de tratamentos dos dados. Houve mesmo evolução, no sentido de que novos problemas ou novas técnicas de tratamento de dados passaram a ser consideradas como melhores, isto é, mais abrangentes e mais esclarecedora do nosso passado,do que as praticadas anteriormente. Ao cotejarmos atualmente as múltiplas formas de análises baseadas em técnicas da demografia histórica com o processo original de L.Henry, talvez possamos até dizer ter havido, desde então,um ou mais "saltos paradigmáticos", mas estes saltos não ocorrerampela completa derrubada de um consenso anterior e, sim, por sucessivas modificações, parciais e graduais nos métodos aplicados.

\section{Agradecimentos}

Agradeço a Cacilda Machado seus pertinentes e atenciosos comentários a este texto, que, embora em alguns aspectos discordantes das conclusões a que chego, me auxiliaram a melhor compreender o tema. Permaneço, contudo, unicamente responsável pela argumentação e conclusões aqui formuladas.

\section{Referências}

AMORIM, Maria Norberta (1991). Uma metodologia de reconstituição de paróquias desenvolvida sobre registros portugueses. Revista de Demografia Histórica, IX-1:7-25. Disponível em: <http://www.adeh.org/?q=es/ system/files/Revista/1991\%2C\%201/N\%20Amorim $\% 2 \mathrm{C} \% 20 \mathrm{IX} \% 2 \mathrm{C} \% 20$ 1\%2C\%201991\%2C\%20pp\%207-25.pdf> (Acesso: 28-ago-2014).

AMORIM, Maria Norberta (2008). Reconstituição de paróquias. Que sentido? Lisboa: Câmara Municipal de Lisboa. Disponível em: <http:// geo.cm-lisboa.pt/fileadmin/GEO/Imagens/GEO/Demografia_historica/ Jornadas_demografia_2008/Demografia_doc2.pdf> (Acesso: 02-ago-2015).

BACELLAR, Carlos de A.P. (1997). Os senhores da terra: família e sistema sucessório entre os senhores de engenho do oeste paulista, 1765-1855. Campinas: CMU/Unicamp.

BACELLAR, Carlos de A.P. (2001), Viver e sobreviver em uma vila colonial:

16 As coletâneas de Bongaarts, Burch \& Wachter (1987) e de Grebenik, Höhn \& Mackensen (1989) incluem textos decisivos para o tema. 
Sorocaba, séculos XVIII e XIX. São Paulo: Annablume-Fapesp. [1994].

BACELLAR, Carlos de A.P. (2014). As fontes para o estudo da família no passado. In: SCOTT, A.S.V. et al. (Orgs.) Mobilidade social e formação de hierarquias: subsídios para a história da população. São Leopoldo-RS: Oikos/Editora Unisinos, p.264-283.

BALHANA, Altiva P. (1986). A população. In: SILVA, Maria Beatriz Nizza da (Ed.). O Império luso-brasileiro, 1750-1822. Lisboa: Editorial Estampa. 19-62p. (Nova História da Expansão Portuguesa).

BALHANA, Altiva P. (1987), Reconstituição de famílias: instrumento de análise demográfica. Rio de Janeiro: Acervo. Revista do Arquivo Nacional, 2-1:53-64.

BALHANA, Altiva P.; NADALIN, Sérgio O. (1980), Análise do ciclo vital a partir da reconstituição de famílias: estudos em demografia histórica. II Encontro de Estudos Populacionais-ABEP. Disponível em: $<\mathrm{http}$ :/www. abep.nepo.unicamp.br/docs/anais/pdf/1980/T80V02A03.pdf> (Acesso: 28ago-2014).

BASSANEZI, Maria Silvia C. B. (1994). Considerações sobre os casos de celibato e a idade ao casar no passado brasileiro. Anais do IX Encontro Nacional de Estudos Populacionais 1:381-395

BONGAARTS, John; BURCH, Thomas K.; WACHTER, Kenneth W. (1987). Family Demography. Methods and their Applications. Oxford: Clarendon Press.

COALE, Ansley J.; WATKINS, S. (Co-Editors) (1986), The Decline of Fertility in Europe. Princeton: Princeton University Press.

COSTA, Iraci Del Nero da (1982). Minas Gerais: estruturas populacionais tipicas. São Paulo: EDEC.

DUPÂQUIER, Jacques (1984). Pour la démographie historique. Paris: Presses Universitaires de France.

FLEURY, Michel; HENRY, Louis (1956). Des registres paroissiaux à l'histoire de la population. Manuel de dépouillement et d'exploitation de l'état civil ancien. Paris: INED;

FLEURY, Michel; HENRY, Louis (1965). Nouveau manuel de dépouillement et d'exploitation de l'état civil ancien. Paris: INED.

FRAGOSO, João (2001). A formação da economia colonial no Rio de Janeiro e de sua primeira elite senhorial (séculos XVI e XVII), In: FRAGOSO, J.; BICALHO, M.F.;GOUVÊA, M.de F., O Antigo Regime nos trópicos: a dinâmica imperial portuguesa. Rio de Janeiro: Civilização Brasileira, p.2971 .

GAUTIER, Etienne; HENRY, Louis (1958). La population de Crulai, paroisse normande. Paris: PUF/INED.

GOUBERT, Pierre (1952), En Beauvaisis: problèmes démographiques du XVIIe siècle. Paris: Annales. Économies, Sociétés, Civilisations, 7-4:453468.

GOUBERT, Pierre (1954), Une richesse historique en cours d'exploitation. Les registres paroissiaux. Paris: Annales. Économies, Sociétés, Civilisations, 9-1:83-93.

GOUBERT, Pierre.(1968), Cent mille provinciaux au XVIIe siècle. Beauvais et le Beauvaisis de 1600 à 1730. Paris: Flammarion. [1960].

GREBENIK, E.; HÖHN, C.; MACKENSEN, R. (1989). Later Phases of the Family Cycle. Oxford: Clarendon Press.

GUILLAUME, Pierre; Jean-Pierre (1970). Démographie historique. Paris: Librairie Armand Colin.

HAJNAL, J. (1965). European Marriage Patterns in Perspective. In: GLASS, D.V.; EVERSLEY, D.E.C. (Eds.). Population in History. London: Edward Arnold. p.101-143.

HENRY, Louis (1948). La mesure de la reproduction et de l'accroissement naturel, Population, 3(2):271-292.

HENRY, Louis (1956). Anciennes familles genevoises. Étude démographique. Paris: PUF/INED;
HENRY, Louis (1967). Manuel de démographie historique. Genève: Librairie Droz.

HENRY, Louis (1977). Técnicas de análise em demografia histórica. Curitiba: UFPR.

HOLLINGSWORTH, T.H. (1964). The demography of the British peerage. Population Studies, XVIII-Nov:1-168.

HOLLINGSWORTH, T.H. (1965). A Demographic Study of the British Ducal Families. In: GLASS, D.V.; EVERSLEY, D.E.C. (Eds.). Population in History. London: Edward Arnold. p.354-378.

KOK, Jan (2007). Principles and Prospects of the Life Course Paradigm, Annales de démographie historique, 113:203-230.

LUNA, Francisco Vidal; COSTA, Iraci Del Nero da; KLEIN, Herbert S. (2009). Escravismo em São Paulo e Minas Gerais. São Paulo: EDUSP/ Imprensa Oficial do Estado de São Paulo.

LUNA, Francisco Vidal; KLEIN, Herbert S. (2005). Evolução da sociedade e economia escravista de São Paulo, de 1750 a 1850. São Paulo: EDUSP.

MACHADO, Cacilda (2006). A trama das vontades: negros, pardos e brancos na produção da hierarquia social (São José dos Pinhais-PR, passagem do XVIII para XIX). Rio de Janeiro: PPGHIS-UFRJ.

MACHADO, Cacilda; ENGEMANN, Carlos; FLORENTINO, Manolo (2003). Entre o geral e o singular. Histórias de fazendas escravistas da Amércia do Sul - séculos XVIII e XIX, In: FLORENTINO, M. \& MACHADO, C. Ensaios sobre a escravidão (I). Belo Horizonte: Editora UFMG, p.167-187.

MARCÍLIO, Maria Luíza (1968). La Ville de São Paulo. Peuplement et population. Rouen: Université de Rouen.

MARCÍLIO, Maria Luíza (2004). Os registros paroquiais e a história do Brasil. Belo Horizonte: Varia Historia, 31:13-20.

MARCÍliO, Maria Luíza.(2006), Caiçara: Terra e População. Estudo de demografia histórica e da história social de Ubatuba. 2. ed. São Paulo: Edusp. [1986].

NADAL, J.; GIRALT, E. (1960). La population catalane de 1553 à 1717. L'immigration française et les autres facteurs de son développement. Paris: SEVPEN-EPHE VI ${ }^{\mathrm{e}}$ Section.

NADALIN, S. O. (1978). Une paroisse d'origine germanique au Brésil: la Communauté Évangelique Lutheriénne à Curitiba entre 1866 et 1969. Paris, Thèse, Doctorat $3^{\mathrm{e}}$ Cycle, EHESS.

NADALIN, S. O. (1988). Sexualidade, casamento e reprodução. Revista Brasileira de Estudos de Populacão, 5-2: 64-94.

NADALIN, Sergio Odilon. A população no passado colonial brasileiro: mobilidade versus estabilidade. Topoi: Revista de História do Programa de Pós-Graduação em História Social da UFRJ, Rio de Janeiro, v. 4, n. 7, p. $222-275,2003$

ROSENTAL, André-Paul; MANDELBAUM, L. (2003), The Novelty of an Old Genre: Louis Henry and the Founding of Historical Demography. Paris: Population (English Edition), 58-1:97-129

ROSENTAL, Paul-André (1997). Thirteen Years of Debate: From Population History to French Historical Demography (1945-1958). Paris: Population: An English Selection, 9:215-241.

SCOTT, Ana Silvia V. (1995). "Família, Casa e Fortuna: Os Grandes Proprietários de Escravos em São Paulo (1765-1836)". Madrid: Boletin de La Asociación de Demografia Histórica, XIII-2: 93-139. Disponível em: $<$ https://www.adeh.org/?q=es/node/6754>(Acesso: 28-ago-2014).

SCOTT, Ana Silvia V. (1999). Famílias, Formas de União e Reprodução Social no Noroeste Português (séculos XVIII e XIX). Guimarães: NEPS Instituto de Ciências Sociais-Universidade do Minho.

SCOTT, Ana Silvia V. (2013). A Historiografia do Cambridge Group: contribuições ao estudo da população, da família e do grupo doméstico. Belém: Revista Estudos Amazônicos, 9-1: 1-31.

SCOTT, Ana Silvia V.; CARDOZO, J.C. da S.; FREITAS, Denize T.L.; SILVA, J.F.da (2014). História da família no Brasil Meridional: temas e perspectivas. São Leopoldo-RS: Oikos/Editora Unisinos. 
SCOTT, Ana Silvia V.; SCOTT, Dario (2006). Cruzamento nominativo de fontes: desafios, problemas e algumas reflexões para a utilização dos registros paroquiais. Encontro Nacional de Estudos Populacionais, 15, 2006, Caxambu: ABEP.

SCOTT, Ana Silvia V.; SCOTT, Dario (2013) Análise quantitativa de fontes paroquiais e indicadores sociais através de dados coletados para sociedades de Antigo Regime.Londrina-PR: Mediações, 18-1:106-124. DOI: 10.5433/2176-6665.2013v18n1p106.

WRIGLEY, E.A. (1966). Family Reconstitution In: EVERSLEY, D.E.C. et al (Eds.). An Introduction to English Historical Demography. London: Weidenfeld and Nicolson, p.96-159. 